Tropical Journal of Pharmaceutical Research January 2017; 16 (1): 43-49

ISSN: $1596-5996$ (print); 1596-9827 (electronic)

(C) Pharmacotherapy Group, Faculty of Pharmacy, University of Benin, Benin City, 300001 Nigeria.

All rights reserved.

Available online at http://www.tjpr.org

Original Research Article

http://dx.doi.org/10.4314/tjpr.v16i1.6

\title{
Anti-tumor activity of polysaccharides extracted from Senecio scandens Buch, -Ham root on hepatocellular carcinoma
}

\author{
Chunqing Dou*, Bao Zhang, Mingming Han, Xin Jin, Liyuan Sun and Tao Li \\ Department of Hepatobiliary Surgery, The First Affiliated Hospital of Chinese PLA General Hospital, Beijing 100048, PR China
}

*For correspondence: Email: dhsdou@126.com; Tel/Fax: +86-010-66848631

Received: 20 September 2016

Revised accepted: 18 December 2016

\begin{abstract}
Purpose: To optimize the extraction conditions of polysaccharides from the root of Senecio scandens Buch,-Ham. (PRS) and evaluate its anti-tumor effect on hepatocellular carcinoma.

Methods: Response surface methodology (RSM) applied with a Box-Behnken design (BBD, three levels and three factors) was employed to determine the effect of extraction time, number of extraction and ratio of water to raw material on the yield of PRS. The anti-tumor effect of PRS on A549, HL60, S180 and H22 cell lines was evaluated in vitro by 3-(4,5-dimethylthiazol-2-yl) -2,5-diphenyltetrazolium bromide (MTT) assay, while in vivo anti-tumor effect was evaluated in H22 tumor transplanted mice. Furthermore, expressions of proteins including caspase-3, caspase-9, Bcl-2 and Bax were determined by western blotting assay.

Results: The established BBD model was highly significant and the optimal conditions were: extraction time, $3.06 \mathrm{~h}$; number of extractions, 2; and ratio of water to raw material, $16.17 \mathrm{~mL} / \mathrm{g}$. PRS showed significant inhibitory effect on $\mathrm{H} 22$ cells $\left(I C_{50}=42.4 \mu \mathrm{g} / \mathrm{mL}\right)$, and significantly inhibited the growth of transplanted H22 tumors in mice at the doses of 20,40 and $80 \mathrm{mg} / \mathrm{kg}(p<0.05, p<0.05$ and $p<0.01$, respectively). Treatment with PRS $(20,40$ and $80 \mu \mathrm{g} / \mathrm{mL})$ significantly up-regulated the expressions of Bax, caspase-3 and caspase-9 in H22 cells, whereas Bcl-2 protein was significantly down-regulated. Conclusion: The results suggest that PRS possesses significant anti-tumor activity on H22 cell line in vitro and in vivo, and the mechanism may be closely related to the induction of mitochondria-mediated apoptosis.
\end{abstract}

Keywords: Senecio scandens, Polysaccharides, Hepatocellular carcinoma, Response surface methodology, Anti-tumor activity, Apoptosis

Tropical Journal of Pharmaceutical Research is indexed by Science Citation Index (SciSearch), Scopus, International Pharmaceutical Abstract, Chemical Abstracts, Embase, Index Copernicus, EBSCO, African Index Medicus, JournalSeek, Journal Citation Reports/Science Edition, Directory of Open Access Journals (DOAJ), African Journal Online, Bioline International, Open-J-Gate and Pharmacy Abstracts

\section{INTRODUCTION}

Hepatocellular carcinoma (HCC) is one of the most common malignant tumors worldwide with a high incidence and mortality [1,2]. Besides surgical management, chemotherapy is another important therapeutic option for HCC, but it would cause severe toxicities which are commonly difficult to tolerate by HCC patients $[3,4]$; for instance, fluorouracil and doxorubicin, two drugs currently used for treating $\mathrm{HCC}$, are not satisfactory since they can produce severe side effects and are not too effective [5]. Thus, searching for new candidate agents with better effectiveness and lower toxicity for treating HCC have received more and more attention.

Traditional Chinese Medicines (TCMs) have a long history in the treatment of various cancers, and they were reported to have low cost and less 
side effects [6,7]. Senecio scandens Buch,-Ham. (Asteraceae), known as "Qianliguang" in Chinese, is one of the most popular species used as a Chinese folk medicine, and it is mainly distributed in southwest China [8]. It is used for the treatment for various ailments, such as enteritis, bacterial diarrhea, respiratory tract infections, and conjunctivitis in China [9]. However, there is no report on the anti-tumor effect of $S$. scandens and its related active components. In the present study, the antitumor effects of polysaccharides extracted from the root of $S$. scandens (PRS) against HCC were investigated, which could lead to further development of PRS as a potential drug for treating HCC.

\section{EXPERIMENTAL}

\section{Chemicals and reagents}

Fetal bovine serum (FBS) and Roswell park memorial institute (RPMI)-1640 culture medium were purchased from Thermo Fisher Scientific (Waltham, MA USA); 5-Fluorouracil (5-FU) and MTT were obtained from Sigma-Aldrich Inc. (St. Louis, MO, USA); primary antibodies of caspase3 , caspase-9, $\mathrm{Bcl}-2$ and $B a x$ were from $R \& D$ Systems, Ltd. (Minneapolis, USA). All the other chemicals and reagents were of analytical grade.

\section{Extraction of polysaccharides from $S$. scandens}

The dried whole plant of $S$. scandens was powdered, and defatted with $95 \%$ ethanol for 24 h. The pretreated powder of $S$. scandens $(50 \mathrm{~g})$ were extracted by refluxing with distilled water at selected extraction times (2, 3 and $4 \mathrm{~h})$, number of extraction (1,2 and 3), and ratio of water to raw material $(10,15$ and $20 \mathrm{~mL} / \mathrm{g})$. After filtration, the solution were concentrated and precipitated with ethanol to a final concentration of $80 \%(\mathrm{v} / \mathrm{v})$ overnight at $4{ }^{\circ} \mathrm{C}$. After centrifugation $(8000 \mathrm{rpm}$ for $10 \mathrm{~min}$ ), the precipitates were collected, and then washed respectively with $95 \%$ ethanol, anhydrous ethanol and acetone. The crude polysaccharides were dried, and the percentage yield (\%) was calculated as the following formula: PRS extraction yield $(\%)=Y_{0} / Y$, where $Y_{0}(g)$ is the weight of dried crude polysaccharides (PRS); $Y(g)$ is the weight of dried powder of $S$. scandens.

\section{Experimental design of response surface methodology (RSM)}

RSM with a Box-Behnken design (BBD, three levels and three factors) was applied to determine the effect of extraction time, number of extractions, and ratio of water to raw material on the extraction yield of PRS. Based on the results of single factor experiment, the experimental range of each factor was determined. The experimental arrangement is shown in Table 1.

\section{Cell culture}

A549, HL60, S180 and H22 cell lines were obtained from the Type Culture Collection of Chinese Academy of Sciences (Shanghai, China). All cells were maintained in RPMI medium supplemented with $10 \% \mathrm{FBS}, 100 \mathrm{U} / \mathrm{mL}$ penicillin and $100 \mu \mathrm{g} / \mathrm{mL}$ streptomycin. The cell lines were cultured in a cell incubator (Thermo Scientific, Waltham, MA, USA) at $37{ }^{\circ} \mathrm{C}$ in $5 \%$ $\mathrm{CO}_{2} / 95 \%$ air.

\section{Animals}

BALB/c mice (18-22 g) were obtained from the Experimental Animal Center of the First Affiliated Hospital of Chinese PLA General Hospital (Beijing, China) and acclimatized for 7 days before they were used for the experiment. The mice were housed under controlled environment (23 $\pm 1^{\circ} \mathrm{C}$ and a 12-h light/12-h dark cycle) with free access to food and water. Research and animal experimental procedures were strictly in accordance with "Principles of Laboratory Animal Care" (NIH publication no. 85-23, revised 1985) and approved by the Animal Care and Use Committee of the First Affiliated Hospital of Chinese PLA General Hospital (approval no. A 90-12-2015t09).

\section{Determination of anti-tumor effect of PRS in vitro}

A549, HL60, S180 and H22 cell proliferations were determined by using MTT assay as previously described [10]. Briefly, cells $(2.0 \times$ $10^{4} / 0.2 \mathrm{~mL}$ ) were seeded into 96 -well plates and allowed to attach for $24 \mathrm{~h}$. A series of concentrations of PRS $(10,20,40,80,160,320$ and $640 \mu \mathrm{g} / \mathrm{mL}$ ) were added and incubated for $48 \mathrm{~h}$. Subsequently, $5 \mathrm{mg} / \mathrm{mL}$ MTT $(10 \mu \mathrm{L})$ solutions were added. After incubating at $37^{\circ} \mathrm{C}$ for $4 \mathrm{~h}$, the supernatant was discarded and dimethyl sulfoxide $(100 \mu \mathrm{L})$ was added to each well. The plates were read at $570 \mathrm{~nm}$ with a Mode 680 96-well microplate reader (Bio-Rad, Tokyo, Japan). Inhibition rate $(\mathrm{H})$ was calculated as in Eq 1.

$H(\%)=\left\{\left(A_{0}-A_{x}\right) / A_{0}\right\} 100$

where $A_{0}$ is the absorbance of controls and $A_{x}$ the absorbance of cells treated with PRS. 
Determination of anti-tumor effect of PRS in vivo

The diluted tumor cells were subcutaneously inoculated $\left(0.2 \mathrm{~mL}, 1 \times 10^{6}\right.$ cells/mouse) into the right armpits of the mice to establish the animal model. After $24 \mathrm{~h}$, mice were divided randomly into five groups. PRS was administered orally (ig) to each group at different dosages (20,40, 80 $\mathrm{mg} / \mathrm{kg}$ ). The positive control group was treated with $5-\mathrm{FU}$ at a dosage of $5 \mathrm{mg} / \mathrm{kg}$ intraperitoneally (ip), and the control group was treated with normal saline (ig). The weights of the mice were recorded before drug administration which lasted for 14 days. On the 15th day, all the mice were sacrificed and the segregated tumor weights were recorded.

\section{Western blot assay}

Western blot assay was used to investigate the apoptotic mechanisms of PRS on H22 cells [11]. Different concentrations of PRS $(20,40$ and 80 $\mu \mathrm{g} / \mathrm{mL}$ ) were added to the $\mathrm{H} 22$ cells and incubated for $48 \mathrm{~h}$. Then, the cells were harvested and total proteins were extracted. Total protein sample $(40 \mu \mathrm{g})$ was separated using SDS/PAGE. The separated proteins were transferred onto polyvinylidene difluoride (PVDF) membrane, and subsequently subjected to immunoblotting analysis with corresponding primary antibodies and horseradish peroxidaseconjugated secondary antibodies (Beyotime Biotech, Haimen, China). After that, chemiluminescence reagents (Beyotime Biotech, Haimen, China) were added for visualization of the protein bands. Antibodies against $\beta$-actin was used to normalize for protein loading.

\section{Statistical analysis}

The data are expressed as mean \pm standard deviation (SD) and were analyzed by ANOVA. Significance of differences between groups was evaluated using Student's $t$-test. RSM was analyzed with Design Expert Version 8.0.5 software (State-Ease, USA). $P<0.05$ was regarded as statistically significant.

\section{RESULTS}

\section{Model fitting and statistical analysis}

As shown in Table 1, independent variables (extraction time, number of extraction, and ratio of water to raw material) on the extraction yield of PRS were examined by BBD design (Table 1).
Multiple regression analysis was performed, and the predicted the yield $(\mathrm{Y})$ of PRS could be obtained by the second-order polynomial equation as in Eq 2.

$Y=6.71+0.091 A+0.61 B+0.27 C-0.005 A B$ $-0.033 A C-0.16 B C-0.72 A^{2}-1.05 B^{2}-0.48$ $\mathrm{C}^{2}$

The analysis results of ANOVA are shown in Table 2. The "lack of fit F-value" (3.01) was not significant due to the relative pure error. Based on the validity analysis of the three variables, it showed that the independent variables of $B$ and $C$, the interaction term of $B \times C$, and the two quadratic terms of $A^{2}, B^{2}$ and $C^{2}$ significantly affected the yield of PRS $(p<0.001)$. The $R^{2}$ and $R^{2}{ }_{\text {Adj }}$ values ( 0.9890 and 0.9750 , respectively) showed a high degree correlation between the observed values and the predicted values. In addition, the statistical analysis also showed a very low $p$-value $(<0.0001)$ and a very high $F$ value (585.70), indicating the established model was highly significant.

\section{Optimized PRS extraction conditions and validated models}

By using the Design-Expert software, 3D graphic surface for the effects of three independent variables are shown in Figure 1. From the model, the optimal conditions for obtaining the highest PRS yield were: extraction time $3.06 \mathrm{~h}$, number of extractions 2.27, and ratio of water to raw material $16.17 \mathrm{~mL} / \mathrm{g}$. The maximum yield of PRS predicted by the model was $6.83 \%$. To validate the accuracy of the model, the optimal condition was modified as follows: extraction time $2.11 \mathrm{~h}$, number of extractions 2 , and ratio of water to raw material $16.17 \mathrm{~mL} / \mathrm{g}$. A verification experiment was carried out under the modified conditions. As a result, the mean yield of PRS obtained from actual experiments was $6.85 \pm 0.12 \%$. The results indicated that the RSM was effective for optimizing the extraction conditions for PRS.

\section{Effect of PRS on cells growth in vitro}

The cytotoxic effect of PRS on A549, S180, HL60 and H22 cell lines were evaluated by MTT assay. As a result, PRS significantly inhibited the cell proliferations of H22, A549, S180 and HL60 cell lines, and the $\mathrm{IC}_{50}$ values were shown in Table 3. PRS showed higher inhibitory effect against the proliferation of $\mathrm{H} 22$ cells $\left(\mathrm{IC}_{50}\right.$ value of $42.4 \mu \mathrm{g} / \mathrm{mL}$ ) than the other cell lines with the highest inhibition ratio of $73.3 \%$ at $320 \mu \mathrm{g} / \mathrm{mL}$. 
Table 1: Experimental design and test results of RSM

\begin{tabular}{ccccc}
\hline S/no. & $\begin{array}{c}\text { A: Extraction } \\
\text { time (h) }\end{array}$ & $\begin{array}{c}\text { B: Number } \\
\text { of extraction }\end{array}$ & $\begin{array}{c}\text { C: Ratio of water } \\
\text { to raw material(mL/g) }\end{array}$ & Yield (\%) \\
\hline 1 & 3.00 & 3.00 & 10.00 & 5.72 \\
2 & 3.00 & 2.00 & 15.00 & 6.73 \\
3 & 4.00 & 2.00 & 10.00 & 5.32 \\
4 & 2.00 & 1.00 & 15.00 & 4.22 \\
5 & 3.00 & 1.00 & 20.00 & 4.98 \\
6 & 2.00 & 2.00 & 10.00 & 5.11 \\
7 & 4.00 & 3.00 & 15.00 & 5.66 \\
8 & 3.00 & 2.00 & 15.00 & 6.72 \\
9 & 3.00 & 1.00 & 10.00 & 4.18 \\
10 & 3.00 & 2.00 & 15.00 & 6.75 \\
11 & 2.00 & 3.00 & 15.00 & 5.45 \\
12 & 2.00 & 2.00 & 20.00 & 5.78 \\
13 & 3.00 & 2.00 & 15.00 & 6.66 \\
14 & 3.00 & 3.00 & 20.00 & 5.87 \\
15 & 3.00 & 2.00 & 15.00 & 6.69 \\
16 & 4.00 & 2.00 & 20.00 & 5.86 \\
17 & 4.00 & 1.00 & 15.00 & 4.45 \\
\hline
\end{tabular}

Table 2: Test results of significance for regression coefficient

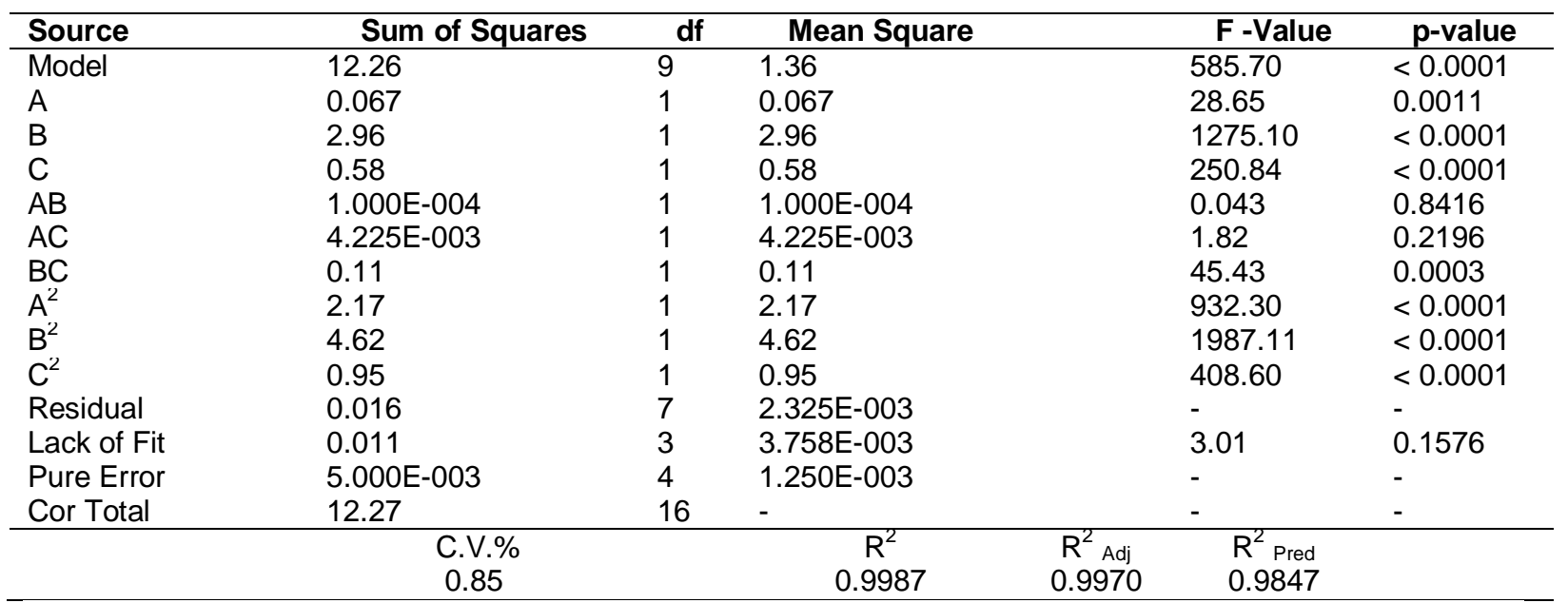

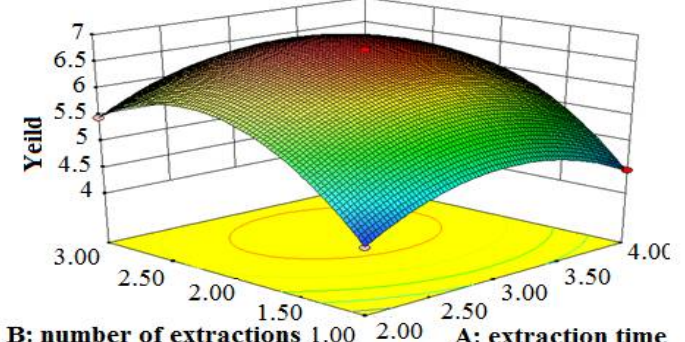

B: number of extractions $1.00 \quad 2.00 \quad$ A: extraction time

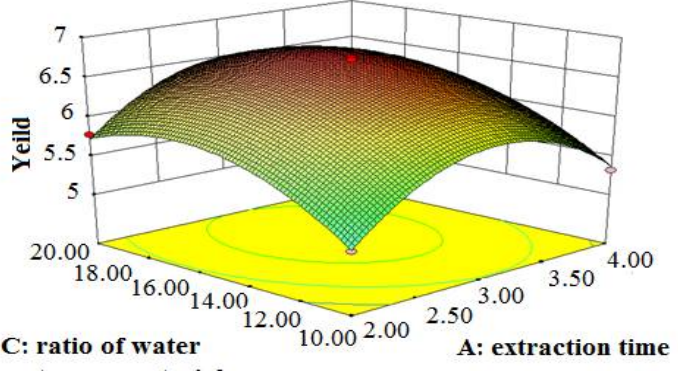

to raw material

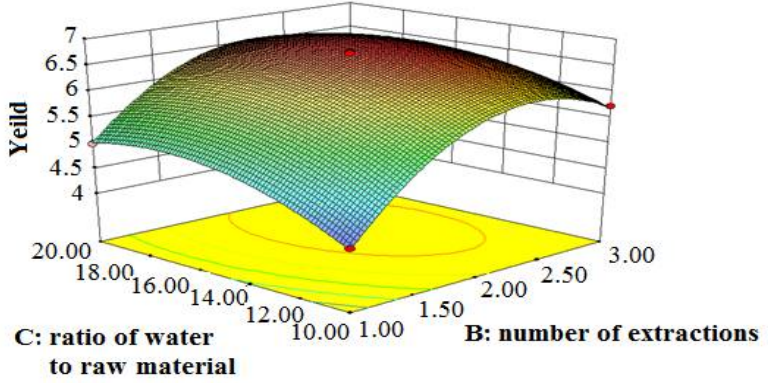

Figure 1: 3D graphic surface for $t$ effects of extraction time, number of extraction, and ratio of water to raw material 
Table 3: $\mathrm{IC}_{50}$ values of PRS on tumor cell lines

\begin{tabular}{lc}
\hline Cell & IC $_{50}$ value \\
\hline H22 & 42.4 \\
A549 & 102.8 \\
S180 & 60.3 \\
HL60 & 117.9 \\
\hline
\end{tabular}

\section{In vivo anti-tumor effect of PRS}

The in vivo antitumor effect of PRS on transplanted $\mathrm{H} 22$ tumors in mice was showed in Figure 2. The results indicated that oral administration of PRS (20, 40 and $80 \mathrm{mg} / \mathrm{kg} ; p<$ $0.05, p<0.05$ and $p<0.01$, respectively) could significantly reduce the tumor weight in a dosedependent manner. Also, the body weights of the mice treated with PRS were higher than that of control, especially at the doses of 40 and 80 $\mathrm{mg} / \mathrm{kg}(p<0.05, p<0.05)$. The 5 -FU could also significantly $(p<0.01)$ reduce the tumor weight, but the body weight of the mice was sharply decreased in this group $(p<0.01)$.

\section{Effect of PRS on expressions of Bcl-2, Bax, caspase-3 and caspase- 9}

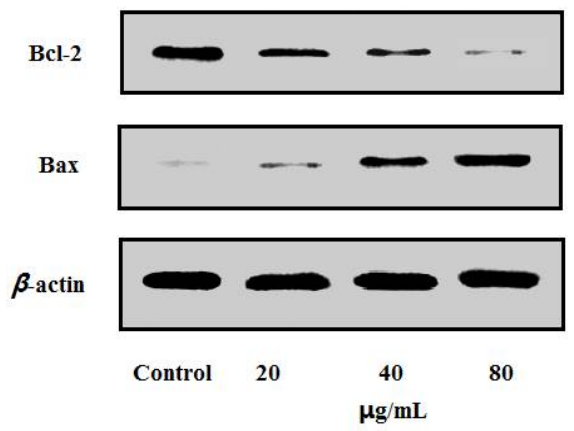

Figure 3: Changes in $\mathrm{Bcl}-2$ and Bax proteins in $\mathrm{H} 22$ cells after treating with PRS

To study the pharmacological mechanisms for the anti-tumor effects of PRS, the effects of PRS

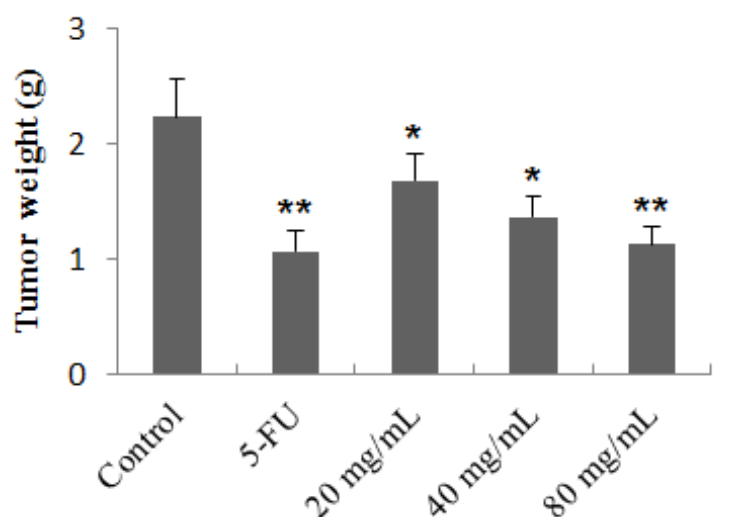

on apoptosis related proteins including $\mathrm{Bcl}-2$, Bax, caspase-3 and caspase- 9 were investigated in $\mathrm{H} 22$ cells. As shown in Figure 3, PRS treatment $(20,40$ and $80 \mu \mathrm{g} / \mathrm{mL})$ significantly upregulated the expression of $\mathrm{Bax}$, and downregulated Bcl-2. Furthermore, similar to Bax, caspase-3 and caspase- 9 were up-regulated following treatment with PRS $(20,40$ and 80 $\mu \mathrm{g} / \mathrm{mL}$ ), compared with the control (Figure 4).

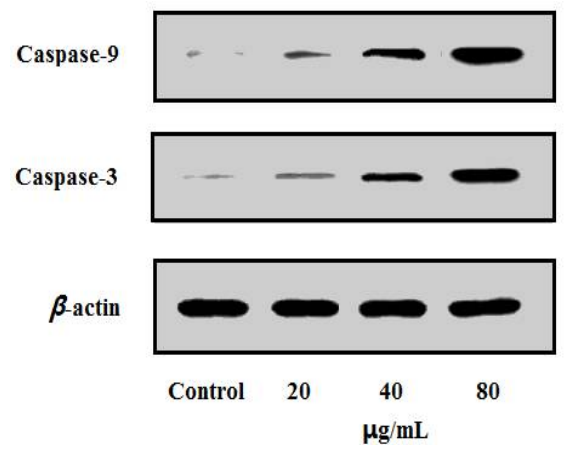

Figure 4: Changes in caspase-3 and caspase-9 proteins in $\mathrm{H} 22$ cells after treating with PRS.

\section{DISCUSSION}

Polysaccharides from various origins including wild plants, fungi and animals are often identified to be biological response modifiers. In recent years, researches on polysaccharides from medicinal plants have attracted much attention because of their potential biological and pharmacological activities, such as anti-tumor, immunomodulating, anti-inflammatory, cardiovascular, antidiabetic and antioxidant activities $[12,13]$. In the present study, polysaccharides from S. scandens (PRS) were extracted and the extraction conditions were optimized by employing response surface methodology (RSM), and furthermore the anti-tumor effects were investigated in vivo and in vitro.

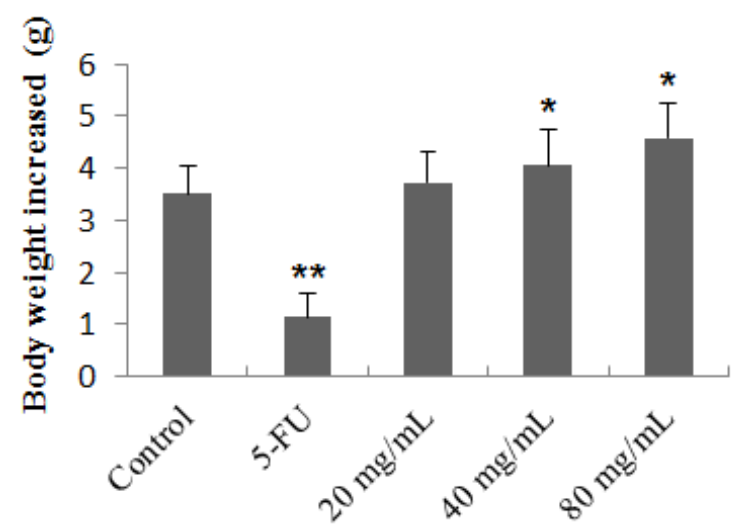

Figure 2: Effect of PRS on transplanted H22 tumor growth and body weight; ${ }^{*} p<0.05$ vs control group; ${ }^{* *} p<$ 0.01 vs control group 
It is well known that RSM is an effective method for optimizing the experimental conditions of complex processes [14]. The main advantage of RSM technique over other statistical techniques is that it can evaluate multiple parameters and their interactions, but the number of experiments needed is reduced [15,16]. Many researches have showed that RSM is an appropriate method used to optimize polysaccharide extraction processes [17,18]. RSM applied with a threelevel three-factor BBD was employed in the present study, and the optimal conditions for PRS were as follows, extraction time, $2.11 \mathrm{~h}$, number of extractions 2, and ratio of water to raw material, $16.17 \mathrm{~mL} / \mathrm{g}$.

There is increasing evidence showed that natural products and many antitumor chemotherapeutic agents can induce apoptosis of cancer cells [19]. It has also been indicated that the ratio of $\mathrm{Bax} / \mathrm{Bcl}-2$ is a key factor in the regulation of the apoptotic process, and a high ratio of $\mathrm{Bax} / \mathrm{Bcl}-2$ might promote apoptosis activity $[19,20]$. Furthermore, caspase- 9 and caspase- 3 are important activators in mitochondria-mediated apoptosis pathway, and caspase- 3 can be activated by caspase-9 [21]. Thus, after treating with PRS, the expression of caspase-9 and caspase-3 proteins were up-regulated and $\mathrm{Bax} / \mathrm{Bcl}-2$ ratio increased in the $\mathrm{H} 22$ cells, indicating that PRS could induce mitochondrialmediated apoptosis.

\section{CONCLUSION}

The findings of the present study indicate that PRS possesses significant anti-tumor effect on $\mathrm{H} 22$ tumor in vitro and in vivo, and that the mechanism of the anti-tumor effect is closely related to the induction of mitochondria-mediated apoptosis.

\section{DECLARATIONS}

\section{Conflict of Interest}

No conflict of interest associated with this work.

\section{Contribution of Authors}

The authors declare that this work was done by the authors named in this article and all liabilities pertaining to claims relating to the content of this article will be borne by them.

\section{Open Access}

This is an Open Access article that uses a funding model which does not charge readers or their institutions for access and distributed under the terms of the Creative Commons Attribution License (http://creativecommons.org/licenses/by 14.0) and the Budapest Open Access Initiative (http://www.budapestopenaccessinitiative.org/rea d), which permit unrestricted use, distribution, and reproduction in any medium, provided the original work is properly credited.

\section{REFERENCES}

1. Lai EC, Lau WY. The continuing challenge of hepatic cancer in Asia. Surgeon 2005; 3: 210-215.

2. Yang J, Li X, Xue Y, Wang N, Liu W. Anti-hepatoma activity and mechanism of corn silk polysaccharides in H22 tumor-bearing mice. Int J Biol Macromol 2014; 64: 276-280.

3. Fan JH, Wang JB, Jiang $Y$, Xiang $W$, Liang $H$, Wei $W Q$, Qiao YL, Boffetta P. Attributable causes of liver cancer mortality and incidence in china. Asian Pac $J$ Cancer Prev 2013; 14: 7251-7256.

4. Harhaji Lj, Mijatović S, Maksimović-Ivanić D, Stojanović I, Momcilović M, Maksimović V, Tufegdzić S, Marjanović $Z$, Mostarica-Stojković M, Vucinić Z. Anti-tumor effect of Coriolus versicolor methanol extract against mouse B16 melanoma cells: in vitro and in vivo study. Food Chem Toxicol 2008; 46: 1825-1833.

5. Nouso K, Miyahara K, Uchida D, Kuwaki K, Izumi N, Omata M, Ichida T, Kudo M, Ku Y, Kokudo N. Effect of hepatic arterial infusion chemotherapy of 5-fluorouracil and cisplatin for advanced hepatocellular carcinoma in the nationwide survey of primary liver cancer in Japan. Br J Cancer 2013; 109: 1904-1907.

6. Jiang S, Qiu L, Li Y, Li L, Wang X, Liu Z, Guo Y, Wang $H$. Effects of Marsdenia tenacissima polysaccharide on the immune regulation and tumor growth in $\mathrm{H} 22$ tumorbearing mice. Carbohydr Polym 2016; 137: 52-58.

7. Peng $W, W u$ JG, Jiang YB, Liu YJ, Sun T, Wu N, Wu CJ. Antitumor activity of 4-O-(2"-O-acetyl-6"-O-p-coumaroyl$\beta$-D-glucopyranosyl)-p-coumaric acid against lung cancers via mitochondrial-mediated apoptosis. Chem Biol Interact 2015; 233:8-13.

8. Qian G, Ping J, Lu J, Zhang Z, Wang L, Xu D. Construction of full-length $C D N A$ library and development of EST-derived simple sequence repeat (EST-SSR) markers in Senecio scandens. Biochem Genet 2014; 52: 494-508.

9. Wang D, Huang L, Chen S. Senecio scandens Buch.Ham.: a review on its ethnopharmacology, phytochemistry, pharmacology, and toxicity. J Ethnopharmacol 2013; 149: 1-23.

10. Liu A, Liu D, Zhao S, Zheng J, Cao D, Zhang H. Up regulation of annexin $A 2$ on murine $\mathrm{H} 22$ hepatocarcinoma cells induced by cartilage polysaccharide. Cancer Epidemiol 2011; 35: 490-496.

11. Lin CH, Chen PS, Kuo SC, Huang LJ, Gean PW, Chiu $\mathrm{TH}$. The role of mitochondria-mediated intrinsic death 
pathway in gingerdione derivative 16-induced neuronal apoptosis. Food Chem Toxicol 2012; 50: 1073-1081.

12. Ge Q, Huang J, Mao JW, Gong JY, Zhou YF, Huang JX. Optimization of total polysaccharide extraction from Herba Lophatheri using RSM and antioxidant activities. Int J Biol Macromol 2014; 67: 37-42.

13. Balavigneswaran CK, Sujin Jeba Kumar $T$, Moses Packiaraj R, Veeraraj A, Prakash S. Anti-oxidant activity of polysaccharides extracted from Isocrysis galbana using RSM optimized conditions. Int $J$ Biol Macromol 2013; 60:100-108.

14. Liu Y, Gong G, Zhang J, Jia S, Li F, Wang Y, Wu S. Response surface optimization of ultrasound-assisted enzymatic extraction polysaccharides from Lycium barbarum. Carbohydr Polym 2014; 110: 278-284.

15. Pu JB, Xia BH, Hu YJ, Zhang HJ, Chen J, Zhou J, Liang $W Q, \quad X U$ P. Multi-optimization of ultrasonic-assisted enzymatic extraction of Atratylodes macrocephala polysaccharides and antioxidants using response surface methodology and desirability function approach. Molecules 2015; 20: 22220-22235.

16. Wang $T, L i C Q$, Zhang $H$, Li JW. Response surface optimized extraction of 1-deoxynojirimycin from mulberry leaves (Morus alba L.) and preparative separation with resins. Molecules 2014; 19: 7040-7056.

17. Bo R, Ma X, Feng Y, Zhu Q, Huang Y, Liu Z, Liu C, Gao $Z$, Hu $Y$, Wang D. Optimization on conditions of Lycium barbarum polysaccharides liposome by RSM and its effects on the peritoneal macrophages function. Carbohydr Polym. 2015; 117: 215-222.

18. Li P, Zhou L, Mou Y, Mao Z. Extraction optimization of polysaccharide from Zanthoxylum bungeanum using RSM and its antioxidant activity. Int J Biol Macromol. 2015; 72:19-27.

19. Wu Z, Sun H, Li J, Ma C, Zhao S, Guo Z, Lin Y, Lin Y, Liu L. A polysaccharide from Sanguisorbae radix induces caspase-dependent apoptosis in human leukemia HL-60 cells. Int J Biol Macromol 2014; 70:615-620.

20. Thees S, Hubbard GB, Winckler J, Schultz C, Rami A. Specific alteration of the Bax/Bcl2 ratio and cytochrome $c$ without execution of apoptosis in the hippocampus of aged baboons. Restor Neurol Neurosci 2005; 23:1-9.

21. Lin CH, Chen PS, Kuo SC, Huang LJ, Gean PW, Chiu $\mathrm{TH}$. The role of mitochondria-mediated intrinsic death pathway in gingerdione derivative 16-induced neuronal apoptosis. Food Chem Toxicol 2012; 50: 1073-1081. 